with the responsibility for ensuring that the Army requirements-and the means of fulfilling them-are projected against the background of modern science and research. In addition to being a member of the Army Council, he is a member of the Ministry of Supply Council and of a number of technical committees of that Ministry. He has under him a scientific adviser to the Ármy Council, who is also a member of the Scientific Advisory Council of the Ministry of Supply.

In the same way the chairman of the Aeronautical Research Committee is also a member of the Air Council and of the Ministry of Aircraft Production Supply Council, thereby giving a scientific link between the Air Ministry and the Ministry of Aircraft Production.

On the whole range of specialist committees, dealing with every aspect of the air programme, the Air Ministry, the Admiralty, and the Ministry of Aircraft Production are represented.

In the main testing establishments there is complete co-ordination between Service and civilian staff, who together carry the responsibility for testing. In a similar way the controller of communications in the Air Ministry is also controller of communications equipment in the Ministry of Aircraft Production and sits as a member of the Radio Board; as also does his vice-controller in my Ministry, who is also scientific adviser on telecommunications to the Secretary of State for Air. In this way we have been able to co-ordinate closely the work between the scientist and the Service user.

I have given these indications of the method of organizing scientific work and co-ordination in order to show that at many levels there is a close integration of the work.

This is not to say that, with ample staff and plenty of time, some better organization might not have been elaborated; ibut it is sufficient, perhaps, to indicate that the Government attaches the very highest importance to the proper utilization of our scientific effort and has gradually built up during the course of the War a machinery which, from the practical utility point of view, has enabled us in many branches of science to keep well ahead of our enemies.

\section{Government and Industry}

A great deal of our scientific strength in Great Britain is of course not in the employment of the Government at all but in the employ of private companies. Many of the great pre-War industrial organizations already had highly skilled research laboratories, which they have extended and which are now working whole-time on Government work.

It is not an easy matter to co-ordinate these organizations, as there has been, in some cases, a not unnatural reluctance for industrial research departments to pool the results of their research, though in other cases this pooling has been done most willingly and to the fullest extent. All these research organizations are, in one way or another, linked up with the various Supply Ministries, though we have not yet reached a perfect method of co-ordination and there is still, I believe, room for a better integration of this section of research and development.

There is one additional feature which $I$ should mention, and perhaps I may do this especially in association with my own Ministry. We have an Aeronautical Research Committee with a number of sub-committees, the members of which are drawn from technical Government staffs and independent scientists with the necessary qualifications. From time to time the membership of these bodies is changed with the view of giving a freshness of outlook; but the difficulty is, of course, now being felt that so many scientists are either in Government or industrial employment that it is not easy to find independent scientists to serve.

In addition to this, there are advisory committees from the industries themselves consisting of engineers or scientists to whom specific problems may be referred or from whom advice may be sought upon the way to tackle definite questions.

I think that our main difficulty with regard to the proper utilization of the scientists in this war has been our failure to realize, at a sufficiently early stage, that this was going to be a truly scientific war, and that the battle would not be won merely by the physical ascendancy of our race but rather by the ingenuity of those who have been trained in our secondary schools, technical colleges, and universities. This realization has gradually grown upon the country and we are now fully alive to the fact that our survival and our victory depend to a great extent upon the output of our scientists and our research institutions, and that everything must be done to utilize to the full that very high degree of scientific intelligence which Great Britain undoubtedly possesses.

We need not be too critical of the exact manner in which that scientific knowledge is made available, provided only that it is made available and that there are no difficulties from those who still, perhaps, fail to realize fully how great a part science must play.

The scientists of Great Britain have undoubtedly achieved the most remarkable progress during the years of the War, but we must do everything in our power to maintain the lead that we have gained; I know that, as in the past our scientists have without stint given their services and their devotion to the country so, too, in the future we can look to them for new implements and new devices which will make our salvation certain and will hasten our victory.

\section{THE PLANNING OF SCIENCE}

A $\mathrm{N}$ open conference on the "Planning of Science" was held in the Caxton Hall, London, on January 30 and 31, under the auspices of the Association of Scientific Workers. Perhaps the most significant comment on the subject was unspoken. For the first time those wishing to confer on the planning of science presented a substantial problem in London traffic control; 30 per cent of those wishing to attend the first session were-despite resort to a remarkably uncomfortable scale of overcrowdingunable to hear the discussion even from the lobbies; overflow accommodation, regrettably unavailable for the first session, had to be made available for the third; the least well-attended session was still a large gathering. No better index of the radical change in public interest need be sought.

Sir Robert Watson Watt, president of the Association of Scientific Workers, at the conclusion of his opening remarks, read a message of greeting dated from Moscow, January 29, 1943, from Vladimir Komarov, president of the Academy of Sciences of the U.S.S.R., and Nikolai Derzhavin, chairman of the Soviet Scientists' Anti-Fascist Committee and mem- 
ber of the Academy of Sciences of the U.S.S.R., in the following terms :

"The role of science is a particularly big one in this War. It was with great satisfaction that we learned that British scientists are devoting their Conference to questions leading to the solution of problems connected with the rapid rout of Hitlerism.

"Since the War broke out Soviet scientists have devoted all their energy to the war effort. Under war conditions, all Soviet scientists have turned their efforts in one direction-to help the Red Army and the industry of the U.S.S.R. This has meant the complete reorganization of all scientific research work. It was necessary to select a fow of the many problems on which the Academy of Sciences of the U.S.S.R. was working, those few which gave an answer to war-time problems.

"The Institutes of the Academy of Sciences selected, from among the subjects being worked on, those which are of importance to the War. The programme which was drawn up in this way was communicated to military organizations, who confirmed the importanee of the subjects mentioned, and added new problems interesting the Army and Navy. After this, we held a number of conferences with leading commanders of the various arms of the Fighting Services and with leaders of the defence industries. The result was that we were able to concentrate the efforts of our scientists on the most important tasks and also to make full use of our numerous institutes and laboratories.

"The results of 1942 show that we have given great help to the Red Army and have been able to provide the front with many new weapons.

"The reorganization of the work of the Academy of Sciences of the U.S.S.R. in order to satisfy the needs of the Army, made a number of organizational measures necessary. In the early days of the War, the Academy of Sciences organized a Commission for the Mobilization of the Resources of the Urals, Western Siberia and Kazakhstan for Defence Needs. This Commission is working under the guidance of the president of the Academy of Sciences of the U.S.S.R., Vladimir Komarov. The significance of the work done by the Commission may be judged by the fact that the workers of the Commission received Stalin Prizes in 1942.

"Three other Commissions are working for the purpose of mobilizing scientists for defence : first, the Naval Technical Commission, consisting of representatives of the Academy of Sciences, naval establishments and scientific research institutes outside the system of the Academy; second, a War Medicine Commission ; third, the Commission for the Mobilization of the Resources of the Volga and Kama Districts for Defence Needs. In addition to the work of strengthening the might of the Red Army, scientists of the Soviet Union are continuing their theoretical investigations.

"Without analysing the measures proposed by you for organization of the work of scientists in your country, measures which are dictated by the specific features of the country concerned, we express our confidence that our colleagues in science will take all necessary measures to hasten the rout of the Hitlerite gangs and bring nearer the complete victory of the United Nations."

The Conference then listened (by the courtesy of the B.B.C.) to a recorded exchange of greetings by trans-Atlantic telephone, between Dr. Harry Grundfest, of the Rockefeller Institute for Medical
Research and national secretary of the American Association of Scientific Workers, and Sir Robert Watson Watt.

\section{The Central Direction}

Sir Stafford Cripps (whose address on "Govemment and Science" is reproduced in full on p. 152 of this issue) outlined the somewhat complex structure of ministerial, departmental and extra-departmental groups concerned with governmental control of science in application to the war effort in Britain. A schematic diagram was included in the exhibition of photographs, diagrams and printed matter which formed part of the Conference. While the diagram is known to contain errors of balance and detail, it is a useful preliminary attempt to bring the present British arrangements into a single picture.

Sir Alfred Egerton presented a corresponding outline of the arrangements in the United States of America.

Dr. David Shoenberg, who has worked under Kapitza in the Institute for Physical Problems of the Academy of Sciences of the U.S.S.R., Moscow, spoke on "Wartime Science in the U.S.S.R.". He supplemented his account of the structure for central direction of the scientific effort in U.S.S.R. by reading the organizational portions of the greetings from Moscow reproduced above. The general organization outlined by Dr. Shoenberg was also represented diagrammatically.

\section{Existing Systems}

It was not unnatural that the detail of the pictures seen across an ocean or half a continent should appear simpler than that of the close-up. But oversimplification in presentation of the less familiar systems of the United States and the U.S.S.R. could not wholly account for the criticisms of that of Great Britain. The Conference may not have judged the organizations catalogued by Sir Stafford Cripps as harshly as did the speaker who quoted Lord Chesterfield's opinion, according to the Duke of Wellington, of the generals of his day: "I only hope that when the enemy reads the list of their names he trembles as I do". There was, however, found no one to go beyond Sir Stafford's qualified enthusiasm: "on the whole ... done as much for us as would any more tidy plan... unless ... worked out well in advance".

Speakers who had first-hand knowledge of conditions in the United States and the U.S.S.R. emphasized the large scale of provision for research, for scientific and technical education, and for the application of science by both these allied nations. The general lavishness of their support for science, the magnificent facilities, the numerical adequacy of the research teams and the scale of technical help and workshop services were all contrasted with the limited provision at home. "Boston Tech." and "Cal. Tech." are the giants of their class, but the somewhat smaller institutes in the U.S.S.R. are no less generously appointed.

Dr. Shoenberg gave an impressive account of the way in which scientific work was from the beginning linked to purpose, and of the "conscious planning" which distributed inter-related problems over a number of institutes, with consequent avoidance of overlapping, and facilitation of collaboration. $\mathrm{He}$ emphasized the scale on which long-term biological research is being maintained in the U.S.S.R. and contrasted this policy with the British policy of diverting 
biologists towards filling gaps left by our inadequate supply of physicists.

The speed with which the gap between research and production could be bridged in the United States was illustrated by the case of a pilot plant for a new explosive-manufacturing process. This plant was in production within thirty days of the conference between the university chemist and the chemical engineers. Sir Alfred Egerton, who gave this example, selected "the high scientific importance of the Industrial Research laboratories" as the greatest difference between the United States and Great Britain.

\section{The Ages of Wisdom}

The most insistent criticism of the existing arrangements in Great Britain was directed against the general failure to bring the young scientific and technical workers in the laboratory or the plant into the formation of policy, the implicit assumption that the most distinguished men are the oldest men, the septuagenarian, octogenarian and (in one case) nonagenarian chairmen, the obstacles preventing the minor member of the scientific democracy bringing his views to the governing body.

It was recognized that the young worker should not be snatched from his productive work to fulltime service in governing or co-ordinating bodies, but it was regarded as impossible for the most modern scientific technique to be represented by the once brilliant laboratory or plant worker who has been so long in 'management' that he is no longer in touch with the thoughts and ways of his immediate successors.

The Conference was reminded of C. K. Mees's dictum that "the man on the job knows most, the Director of Research very little, the committee of Vice-Presidents nothing at all".

There was constant emphasis on the need for planning and co-ordination from below, to complement and consolidate with planning and co-ordination from above.

Closely related to this group of comments was that which called for direct contacts between the relatively junior executive officers in the Fighting Services and the junior scientific workers who could solve the problems posed by their serving contemporaries.

\section{A Central Scientific and Technical Board}

Mr. E. D. Swann, speaking for the executive of the Association of Scientific Workers, reviewed the deficiency in the applications of science to the war effort which the Association discussed in its earlier Conference, and the partial rectification which has been achieved in the intervening year. These deficiencies include failure to pool information and facilities, to concentrate effort on vital war needs only, to ensure full co-ordination between Government departments and between these departments and industry, to utilize fully the initiative of the individual worker.

Towards the fuller rectification of these defects the Association proposes the setting up of a Central Scientific and Technical Board, composed of scientifically and technically qualified persons. This Board would be in direct contact with the War Cabinet and able to raise items on its agenda. In this important respect the proposed Board would differ from the existing advisory bodies. Its functions would be to advise the War Cabinet on seientific matters and to relate the country's scientific effort to the strategy determined by the War Cabinet. In relation to science the Board would possess executive powers enabling it to survey scientific problems, to allocate priorities to the various problems and the necessary resources to deal with them. It would establish the date by which scientific projects should reach completion and review their progress and the resources allocated to them from time to time. The Board would need the authority to initiate or stop programmes of work and to transfer personnel where necessary. It would also need powers to demand any scientific or technical data from any firm or industrial department.

It was clearly recognized that over-planning of science may produce a greater measure of frustration than does our present scale of under-planning. What is sought is a system which will make it easy for the individual scientific and technical worker to give his full effort, with adequate facilities, in that grouping which is best adjusted to the need of the moment, and with an understanding of the broad reasons for its programme in relation to that need.

"We do not want the individual worker to spend a large part of his time explaining to central planning boards what he would have been doing if he had not been explaining to them. We do want the central boards to help the workers to do their work better, by explaining to them why they are asked to do certain things in a certain grouping at a certain time. But mainly we want to ensure that the things and the grouping and the timing are part of one integrated plan of utilization."

\section{Science and the Soldier}

Air Chief Marshal Sir Philip Joubert said "the association of science and the fighting man is no new thing. But perhaps it has reached its highest development during the adolescence of the Royal Air Force". He described the "harmonious co-operation of science and the military art which achieved outstanding success in the Battle of Britain".

Sir Philip's main theme was the growth, the essential nature, and the necessary limits of operational research.

"The desirable situation is when the Service side realizes a series of needs and passes straightforward questions to the scientist. Such questions must, of course, be capable of consideration by scientific methods. By this I mean they must be questions of fact, not of theory. The facts of the war in the air can be clearly stated. For example, it may be necessary to decide how many flying hours with so many aircraft are required to achieve a certain result. Given past experience, scientific analysis will quickly provide the answer to this question. Naturally, all the questions are not so simple in form.

"The position becomes more complicated when the military staff are not quite certain what they want and are unable to state their case clearly. The scientist then must grope for his solution and it is here that a very serious difficulty may arise.

"The prosecution of war is, in principle, an art. The methods to be employed are based on past experience and study, but their application to a particular problem must be a matter of judgment. The military man, by education and experience, if he is to succeed, must have this judgment. The scientist is not fitted, either by his training or his experience, to exercise that judgment. But if he is insufficiently guided by the military staff, in the course of his researches he is almost certain to trespass into the realm of military art. It is therefore of the 
utmost importance that the military staff should give the scientist the clearest guidance on his duties.

"If, however, the scientist never initiates any action and always waits to be asked a question by the military staff, he will lose half his value. It is a truism to say that the solution to a problem which puzzles those who are constantly working on it is often grasped very quickly by a new-comer, and it is certain that the advent of the Operational Research Sections has resulted in many difficulties being cleared away by the sound advice they have given. I must, however, insist upon the point that this advice should be confined to the purely factual aspect of any problem. To my mind it is not the business of Operational Research Sections to advise on future operations. They can examine past operations and draw conclusions from them, but it is for the military staffs to apply these conclusions as modified by their military judgment."

The natural extension of the methods of operational research into post-war life generally was treated by a member of an operational research staff in a thoughtful and stimulating contribution, one of several from which the importance of operational research methods emerged very clearly.

\section{Science and the Educational System}

It was noteworthy that the first and the last addresses to the Conference, as well as many between, ascribed the major obstacles to full utilization of science in the service of humanity to the unbalance in education between science and the 'humanities'. This diminishing but persisting unbalance, it was stated, accounts for the famine of scientific and technical workers which now faces us. It accounts, too, for the disproportionate effort required to convey to the administrators, the politicians and the industrialists the true nature of science in the service of civilization, its method and its possibilities.

It is, however, impossible to await the radical cure, which requires first the re-education of our educators. The process must be undertaken, but we must simultaneously take measures which will have earlier effect.

\section{Science and Parliament}

The Parliamentary and Scientific Committee owes to the Association of Scientific Workers alike its foundation and its resuscitation from the remarkable suspension of its activities which was decided on at the beginning of the War. The Committee goes far towards solution of the problem of acquainting Parliament with scientific opinion on all matters of current importance. It aids the presentation of questions and resolutions in Parliament, and approach to Ministers by deputation and interview.

Lord Hinchingbrooke offered advice to the Conference on the technique of bringing scientific ideas into the forum of Parliament. He said that politicians are people who know a little about a very great deal, and urged the need for showing clearly the application of any idea presented, and for avoiding dilution of important information by its inclusion in bulky and frequent collections of miscellaneous matter.

Prof. S. Chapman, while refusing to accept politics as anything higher than a regrettable necessity in the relations of science and the community, is convinced that scientific workers should be of and among the legislators, should be in the Mother of Parliaments as of right and of duty. Science should be recognized as one of the Estates of the Realm, and should have its life representatives in the Upper House. These "bishops of science", men and women, should be chosen by the scientific workers themselves, and should come from the age groups of the thirties and forties as well as from the fifties and sixties. They should number twenty rather than two, they would not necessarily be the very best scientists, but should have knowledge of politics and affairs in addition to their scientific knowledge.

\section{Science and Industrial Managements}

Colonel W. C. Devereux, managing director of High Duty Alloys, Ltd., spoke as a "professional manager", from that inarticulate class called "management".

"I hope I am right in believing that the day is past for ever when the scientific worker in industry-the works chemist or metallurgist-was regarded by the management as a necessary evil; as someone who should be put away quietly in a dirty little shack miscalled a laboratory, and brought out only to put on the carpet and abused for anything that had gone wrong, or to produce an immediate solution to any troubles which would not yield to more direct methods of attack. To-day, the value of scientific research and control is appreciated by progressive management as an essential part of a manufacturing organization. I do not believe that good management, and by this I mean competent men who understand the technical processes they control, finds any great difficulty in interpreting and applying the recommendations of the scientific workers. The greater difficulty is to convey to the scientist the problems requiring solution and to direct him along the right lines of investigation."

Kettering, of General Motors, sums up the position very wisely when he says : "It may not always be the best policy to adopt a course that is best technically, but those responsible for policy can never form a right judgment without knowledge of what is right technically".

After outlining the organization of the scientific and technical staff in his own companies - on a scale exceptional in industry-Col. Devereux quoted the results of two investigations initiated by his economy committee, one for fuel economy in which the $£ 35,000$ capital expenditure incurred in providing re-designed combustion chambers and the like was saved within the first year of use, and one for modifications in a bought-out material, the cost of the investigation being repaid by the savings on a single day's purchases.

Col. Devereux was critical alike of the research associations and of the existing national laboratories. The former "have not so far been a really important factor in industrial development. This is readily understandable when one considers the . . . lack of backing which these organizations receive from industry and the Government." "Our existing national laboratories . . . sometimes become a sort of blissful oasis where certain scientific gentlemen can browse in quiet seclusion to their hearts' content." His constructive prescriptions for a better state of things deserves more space than can be given in this summary of nine hours of wide-ranging discussion; he proved himself a powerful and stimulating friend of the scientific worker.

\section{Joint Production Committees}

A substantial proportion of the detailed discussion on the immediate fuller application of scientific and technical knowledge to war production was devoted to the problem of Joint Production and Advisory Committees in industry. The Association noted with special satisfaction the acceptance by the Minister of 
Aircraft Production of its contention that scientific and technical staffs should have their own representation alongside 'management' and 'labour' in these committees. The strength of the resentment felt by the Conference in relation to "the deliberate policy of the Employers' National Federation to exclude from the Joint Production and Advisory Committees any representatives of the staff" was unmistakable.

A representative from Hayes made a valuable contribution describing the success of local eooperation between scientific and technical staff and other organized groups of the labour force towards mitigating the evils resulting from this exclusion from Joint Production Committees. Only one speaker was able to present himself as an actual member of such a Committee, although another was able to underline the absurdity of a situation in which one technical worker, excluded from membership of a Joint Production Committee, has already been coopted to the Committee on four separate occasions to help in the consideration of special problems.

\section{International Co-operation}

Throughout the discussion there was constant reference to the need for closer inter-Allied co-operation, and in particular to the need for wide extension of the existing arrangements by which young workers from the war laboratories visit their colleagues in other countries, not merely for discussion but also for work side by side in Allied teams. It was emphasized by Sir Robert Watson Watt that only the indispensables should be spared from this vital work.

The inadequacy of the initial response by the United States and Great Britain alike to the U.S.S.R. offer of help on the synthetic rubber problem was cited as an example of grievous failure in inter-Allied co-operation, not yet incapable of rectification. Immediate action, again by way of a personal mission of young and active workers, was called for.

\section{Determining the Future}

The contributions by Sir Lawrence Bragg, "The Position of Scientists after the War", by Prof. P. M. S. Blackett on "The Rehabilitation of Fundamental Research", and by Prof. H. Levy on "The Basis of Scientific Planning", introduced the discussion, in the third and final session of the Conference, on "Determining the Future". The proceedings at this long and crowded session were of such importance that they merit separate treatment. No attempt is, therefore, made to summarize them in the present review.

\section{Summary}

The points on which the most vigorous criticism, and pressure for reform, were expressed in the Conference were:

(1) The need for a stronger, simpler and more closely knit fabric of central direction of scientific effort in the War, controlled by active scientific workers with full knowledge of War Cabinet policy and current strategy.

(2) The need for constant participation by the young scientific worker in the shaping and direction of policy and in its execution.

(3) The need for direct interchange of view between the junior user and the junior scientific worker. (This was admirably summed up by Mr. Hilton Brown in a broadcast to schools on February 2, in which he showed the junior military officer and the junior scientific officer at the foot of the two legs of the letter $\mathrm{A}$, without adequate provision of bridges below the apex.)

\section{PLACE OF RESEARCH IN THE CONTROL OF INJURIOUS INSECTS*}

\author{
BY Prof. J. W. MUNRO \\ Imperial College of Science and Technology
}

$\mathrm{T}^{\mathrm{T}}$ is well to remember that it is not necessary nor 1 is it even practicable wholly to exterminate populations of injurious insects. For example, the Ministry of Agriculture has found that the growing of wheat on land carrying a population of wireworms of 600,000 per acre is economic, but on land carrying a higher population it is risky. It follows that if on heavily infested land the wireworm population could be reduced below 600,000 per acre the growing of wheat would be economical and for practical purposes control would be achieved.

As an example of the different kinds of work or investigation which the control of injurious insects entails I propose to take the control of insects affecting food-stuffs and other produce during transit and storage. These insects are, especially in wartime, a potential danger to the national economy, and methods of controlling them are only now being developed in Great Britain.

In $1929 \mathrm{I}$ was asked by the Australian Dried Fruits Board to advise and assist them in dealing with infestation of sultanas and raisins by the phycitid moth Plodia interpunctella. The infestation occurred in these dried fruits on their arrival in London, and persisted and increased during storage in the warehouses prior to marketing.

The facts concerning this infestation and the measures which had then been taken to combat it were these. Infestation undoubtedly occurred in the drying and packing sheds of the fruit growers in Australia. It occurred in the packages of the fruit on shipment, and on the voyage from Australia to England became aggravated during the passage through the tropics. Measures were being taken in Australia to reduce infestation and, in Great Britain, a system of fumigation of all incoming fruit had been introduced. Cases of fruit arriving on shipboard in the Thames were transferred to barges for delivery to various warehouses up river, and all these cases were fumigated. A further step towards control was taken at that time by centralizing storage in a single group of warehouses instead of spreading it over many warehouses, and it seemed as if the prospect of control was promising. In 1929, however, it became evident that these measures were unavailing and it was then that I accepted responsibility for a review of the whole question of control to be practised in Great Britain and for the conduct of such investigations as might be necessary to ensure it.

A rapid survey of the conditions then prevailing showed that failure to achieve control was caused by the inefficiency of the fumigation of the fruit in barges and chambers, and it became necessary to investigate this. It soon became evident that fumigation practice was wholly empirical and that that could only "be remedied by investigation of a number of problems. The more important of these concerned methods of determining the concentration of the gas obtained during the fumigation both in the air space of the barge or chamber and on and within the sultanas and raisins. Then came the need to * Substance of a discourse before the Royal Institution on Decem. ber 18 . 